\title{
Hemoglobin A1c and preoperative glycemia as a decision tool to help minimise sternal wound complications: a retrospective study in OPCAB patients
}

Jef Van den Eynde ${ }^{1}$, Abel Van Vlasselaer ${ }^{1}$, Annoushka Laenen², Delphine Szecel', Bart Meuris ${ }^{1}$, Tom Verbelen$^{1}$, Steven Jacobs ${ }^{1}$, Peter Verbrugghe ${ }^{1}$ and Wouter Oosterlinck ${ }^{1 *}$ (i)

\begin{abstract}
Background: Poor glycemic control has been associated with an increased risk of wound complications after various types of operations. However, it remains unclear how hemoglobin A1c ( $\mathrm{HbA} 1 \mathrm{c})$ and preoperative glycemia can be used in clinical decision-making to prevent sternal wound complications (SWC) following off-pump coronary artery bypass grafting (OPCAB).

Methods: We conducted a retrospective study of 1774 consecutive patients who underwent OPCAB surgery between January 2010 and November 2016. A new four-grade classification for SWC was used. The associations of $\mathrm{HbA1C}$ and preoperative glycemia with incidence and grade of SWC were analysed using logistic regression analysis and proportional odds models, respectively.

Results: During a median follow-up of 326 days (interquartile range (IQR) 21-1261 days), SWC occurred in 133/1316 $(10 \%)$ of non-diabetes and $82 / 458(18 \%)$ of diabetes patients $(p<0.001)$. Higher HbA1c was significantly associated with a higher incidence of SWC (odds ratio, OR 1.24 per 1\% increase, 95\% confidence interval, Cl 1.04;1.48, $p=$ $0.016)$ as well as a higher grade of SWC (OR 1.25, 95\% Cl 1.06;1.48, $p=0.010)$. There was no association between glycemia and incidence $(p=0.539)$ nor grade $(p=0.607)$ of SWC. Significant modifiers of these effects were found: $\mathrm{HbA1C}$ was associated with SWC in diabetes patients younger than 70 years (OR 1.41,95\% Cl 1.17;1.71, $p<0.001)$, whereas it was not in those older than 70 years. Glycemia was associated with SWC in patients who underwent non-urgent surgery $(\mathrm{OR} 2.48,95 \% \mathrm{Cl} 1.26 ; 4.88, p=0.009)$, in diabetes patients who received skeletonised grafts (OR $4.83,95 \% \mathrm{Cl} 1.28 ; 18.17, p=0.020)$, and in diabetes patients with a $\mathrm{BMl}<30(\mathrm{OR} 2.19,95 \% \mathrm{Cl} 1.01 ; 4.76, p=0.047)$, whereas it was not in the counterparts of these groups.
\end{abstract}

Conclusions: Under certain conditions, HbA1c and glycemia are associated SWC following OPCAB. These findings are helpful in planning the procedure with minimal risk of SWC.

Keywords: Diabetes mellitus, Glycemia, HbA1c, OPCAB, Sternal wound complications, Sternal wound infections

\footnotetext{
* Correspondence: wouter.oosterlinck@uzleuven.be

'Department of Cardiovascular Diseases, Research Unit of Cardiac Surgery,

University Hospitals Leuven, Herestraat 49, 3000 Leuven, Belgium

Full list of author information is available at the end of the article
}

(c) The Author(s). 2021 Open Access This article is licensed under a Creative Commons Attribution 4.0 International License, which permits use, sharing, adaptation, distribution and reproduction in any medium or format, as long as you give appropriate credit to the original author(s) and the source, provide a link to the Creative Commons licence, and indicate if changes were made. The images or other third party material in this article are included in the article's Creative Commons licence, unless indicated otherwise in a credit line to the material. If material is not included in the article's Creative Commons licence and your intended use is not permitted by statutory regulation or exceeds the permitted use, you will need to obtain permission directly from the copyright holder. To view a copy of this licence, visit http://creativecommons.org/licenses/by/4.0/. The Creative Commons Public Domain Dedication waiver (http://creativecommons.org/publicdomain/zero/1.0/) applies to the data made available in this article, unless otherwise stated in a credit line to the data. 


\section{Background}

Sternal wound complications (SWC) remain a feared complication after coronary artery bypass grafting (CABG). According to the extensiveness of the infection, SWC can be classified into superficial, deep, and organ/ space infections [1]. Deep incisional infection and mediastinitis are the least common and are usually reported together as deep SWC (DSWI) [2]. Although the incidence of DSWI is only $0.5-3 \%$, it is associated with a significant risk of mortality, prolonged hospital stay, and increased medical costs [3-5]. In fact, any type of SWC can be a considerable burden for the patient.

The process of wound healing is complicated and requires the integration of various overlapping events [6]. Although several checks and balances are present, the process can be disrupted by conditions such as vascular insufficiency, immunodeficiency, stress, and chronic diseases. Especially type 2 diabetes mellitus has become an increasingly common risk factor in the population undergoing $\mathrm{CABG}$, as currently one out of two CABG patients have diabetes [7]. The glycemic fluctuations and prolonged hyperglycemia which are typical for diabetes can trigger oxidative stress and promote proinflammatory responses [8]. The idea that glycemic dysregulation can increase the risk of poor wound healing is further supported by many studies that have associated diabetes with increased rates of SWC following CABG [9-11].

Poor glycemic control results in an elevated hemoglobin A1c (HbA1c), a biomarker which is widely used to diagnose and follow up on the treatment of diabetes patients [12]. As glycemia and HbA1c are markers of acute and chronic glycemic control, respectively, it has been hypothesized that they might be useful tools in clinical decision making regarding the prevention of SWC. However, it remains unclear how HbA1c and preoperative glycemia can be used in clinical decisionmaking to prevent SWC. The aim of this study was to investigate the association of $\mathrm{HbA1c}$ and preoperative glycemia in a population undergoing off-pump coronary artery bypass grafting (OPCAB).

\section{Methods}

\section{Population and study design}

This study conforms to the ethical guidelines of the 1975 Declaration of Helsinki as reflected in a priori approval by the local Ethical Committee of the University Hospitals of Leuven. The data from 1900 consecutive patients who underwent OPCAB surgery at the University Hospitals of Leuven between January 2010 and November 2016, were studied. All diabetes and nondiabetes patients who had received one or more conduits were eligible for inclusion. We excluded 126 patients who did not have at least one glycemia or HbA1c value, thus leaving 1774 patients in our database: 1316 nondiabetes patients and 458 diabetes patients. Data on patient follow-up was obtained through available information in their electronic medical records, as well as hospitalisations and outpatient surgical and cardiology consultations. Minimal period of follow-up for every patients was until hospital discharge or death.

Demographic characteristics and perioperative variables were considered and compared between both groups. Demographics included age, gender and body mass index (BMI). Comorbidities such as diabetes, organ transplantation, chronic obstructive pulmonary disease (COPD) with need of bronchodilator treatment, and use of oral corticosteroids were analysed. Perioperative information contained the harvesting method, the use of single (SIMA) or bilateral internal mammary arteries (BIMA), and whether the surgery was an urgency. The major postoperative outcomes were the incidence and grade of SWC. Another outcome was the overall survival.

The primary variables of interest were preoperative glycemia and HbA1c. All selected HbA1c values had been measured within a time frame of 3 months from the date of surgery. In the case of multiple available HbA1c values, the value closest to the date of surgery was selected. HbA1c was also collected in a subset of non-diabetes patients. In the analyses, values $>300 \mathrm{mg} /$ $\mathrm{dL}$ for glycemia were regarded as outliers and excluded.

Because commonly used classifications such as the STS classification of deep sternal wound infections only include severe types of infection, we have previously introduced a new classification for a more comprehensive definition of wound complications [13]. This classification, as given in Table 1, consists of four severity grades. Grade 1 and 2 are mild and superficial sternal wound problems or infections with minimal impact on patient recovery, while grade 3 and 4 are severe and deep complications that need subsequent surgical interventions. The majority of the SWC were diagnosed at the time of hospitalisation.

\section{Surgical procedure}

All operations were led by one of 7 in-house cardiothoracic surgeons. As mentioned earlier, all patients underwent OPCAB surgery in which median sternotomy was the standard access strategy. The IMA was used as the main graft vessel for myocardial revascularisation. Either SIMA or BIMA were used. Between January 2010 and December 2014, conventional non-skeletonised technique was used to harvest the IMA in all patients $(n=$ 1487). From January 2015 to November 2016, all patients $(n=413)$ received a skeletonised IMA graft. When the skeletonised technique was used, the IMA was isolated from the thoracic wall using meticulous dissection, 
Table 1 Grading of sternal wound complications

\begin{tabular}{ll}
\hline Grade 1: Minor & $\begin{array}{l}\text { Superficial wound problem: local redness or minimal drainage } \\
\text { Conservative approach, spontaneous healing }\end{array}$ \\
Grade 2: Superficial & Wound infection: positive culture \\
Grade 3: Moderate & Antibiotic treatment \\
Grade 4: Severe & Deep wound infection: dehiscence \\
& Need for drainage, debridement, or VAC \\
& Mediastinitis or mechanical sternal dehiscence \\
\hline
\end{tabular}

VAC vacuum assisted closure

leaving the adjacent vein, fat tissue, endothoracic fascia, parietal pleura and intercostal muscle undisturbed. Dissection was performed using electrocautery, and arterial side branches were divided using hemoclips and microscissors. In the non-skeletonised technique, the IMA was dissected along with the surrounding tissues using electrocautery. All IMA grafts were mobilised from the first rib to the bifurcation of the IMA into the superior epigastric and musculophrenic arteries.

Optimal wound management was pursued in all patients. Preoperative infection prophylaxis has widely remained the same in the time period this study covers. Patients had a preoperative chlorhexidine bath and the surgical site was clipped. Antibiotic prophylaxis was given by intravenous administration of $3 \mathrm{~g}$ of cefazolin before incision and $2 \mathrm{~g}$ every $3 \mathrm{~h}$ intraoperatively. Tight glycemic control was attained pre-, per- and postoperatively. Bone wax was used according to needs. The sternum was closed using 8 to 10 single steel wires, and subsequently the fascia and subcuticular tissues were approximated separately using a running suture.

\section{Statistical analyses}

Continuous variables were checked for normality and the difference between groups was tested with the t-test or Mann-Whitney U test accordingly. Categorical variables are expressed as frequency and proportion, and differences were assessed with the Chi-square test. We analyzed SWC as an ordinal variable and as a dichotomous variable. The association between preoperative glycemia or HbA1c and the ordinal SWC grade was analysed using proportional odds models, whereas the incidence of SWC was investigated with logistic regression analysis. Adjustment was performed by using multivariable models, including these patient characteristics in the analysis model on which groups were different. Interactions of HbA1c and glycemia with other variables were also investigated. Analyses were performed for the entire study population, but also for non-diabetes and diabetes patients separately. All tests were two-sided and a $p$-value less than 0.05 was deemed statistically significant. All analyses have been performed using SAS software (version 9.4; SAS Institute, Cary, NC).

\section{Results}

\section{Study population}

Demographics of the study population are given in Table 2. Diabetes patients were comparable to nondiabetes patients for most variables except for a higher BMI $\left(27.9 \pm 4.93 \mathrm{~kg} / \mathrm{m}^{2}\right.$ vs $26.6 \pm 4.04 \mathrm{~kg} / \mathrm{m}^{2}$ for diabetes and non-diabetes, respectively, $p<0.001)$ and a lower use of BIMA grafts $(54.8 \%$ vs $64.2 \%, p<0.001)$. Furthermore, diabetes patients had a higher preoperative glycemia $(131.3 \pm 40.3 \mathrm{mg} / \mathrm{dL}$ vs $107.0 \pm 24.3 \mathrm{mg} / \mathrm{dL}, p<$ $0.001)$ and HbA1c $(6.91 \pm 1.22 \%$ vs $5.80 \pm 0.79 \%$, $p<0.001)$.

\section{Association of hemoglobin A1c and glycemia with sternal wound complications}

In this cohort, the median follow-up was 326 days (interquartile range (IQR) 21-1261 days). During follow-up, SWC occurred in $215(12.12 \%)$ patients: $133(10 \%)$ of non-diabetes and $82(18 \%)$ of diabetes patients $(p<$ 0.001). Table 3 lists the incidence of SWC per grade.

Among the full study cohort, patients with SWC were more often female $(27.0 \%$ vs $18.2 \%$, for SWC and no SWC, respectively, $p=0.002)$, had a higher BMI (28.9 \pm $5.03 \mathrm{~kg} / \mathrm{m}^{2}$ vs $\left.26.7 \pm 4.15 \mathrm{~kg} / \mathrm{m}^{2}, p<0.001\right)$, and had a higher use of BIMA grafts $(75.4 \%$ vs $59.9 \%, p<0.001)$ (Table 4). Those who developed SWC had a higher HbA1c $(7.03 \pm 1.42 \%$ vs $6.60 \pm 1.18 \%, p=0.007)$. The adjusted models revealed that a higher HbA1c was significantly associated with a higher incidence of SWC (odds ratio, OR 1.24 per $1 \%$ increase, $95 \%$ confidence interval, CI 1.04;1.48, $p=0.016$ ) as well as a higher grade of SWC (OR 1.25, 95\% CI 1.06;1.48, $p=0.010$ ) (Table 5). Patients who developed SWC had similar preoperative glycemia $(116.6 \pm 35.5 \mathrm{mg} / \mathrm{dL} \quad$ vs $112.8 \pm 30.5 \mathrm{mg} / \mathrm{dL}, \quad p=0.094)$ (Table 4). The adjusted models revealed no association between preoperative glycemia and incidence $(p=0.539)$ nor grade $(p=0.607)$ of SWC (Table 5$)$. The estimated probabilities with $95 \%$ confidence interval for sternal 
Table 2 Demographic characteristics and perioperative variables

\begin{tabular}{|c|c|c|c|c|}
\hline Variable & All $(n=1774)$ & Non-diabetes $(n=1316)$ & Diabetes $(n=458)$ & $P$ \\
\hline Age, years & $67.9 \pm 9.65$ & $68.0 \pm 9.84$ & $67.3 \pm 9.09$ & 0.068 \\
\hline Male gender & 1433 (80.78) & $1075(81.69)$ & $358(78.17)$ & 0.100 \\
\hline $\mathrm{BMI}, \mathrm{kg} / \mathrm{m}^{2}$ & $26.9 \pm 4.33$ & $26.6 \pm 4.04$ & $27.9 \pm 4.93$ & $<0.001$ \\
\hline \multicolumn{5}{|l|}{ BMI group } \\
\hline$<25$ & $486(28.86)$ & $390(31.3)$ & $96(21.9)$ & \multirow[t]{4}{*}{$<0.001$} \\
\hline $25-29$ & 789 (46.85) & $593(47.6)$ & $196(44.7)$ & \\
\hline $30-34$ & 331 (19.66) & $220(17.7)$ & $111(25.3)$ & \\
\hline$>34$ & $78(4.63)$ & $42(3.37)$ & $36(8.20)$ & \\
\hline Urgent surgery & $864(48.70)$ & $630(47.87)$ & $234(51.09)$ & 0.235 \\
\hline Oral corticosteroids & $145(8.17)$ & $103(7.83)$ & $42(9.17)$ & 0.366 \\
\hline Transplantation & $16(0.90)$ & $8(0.61)$ & $8(1.75)$ & 0.026 \\
\hline COPD & $110(6.20)$ & 78 (5.93) & $32(6.99)$ & 0.418 \\
\hline Skeletonisation & $384(21.65)$ & $271(20.59)$ & $113(24.67)$ & 0.068 \\
\hline BIMA & $1096(61.78)$ & $845(64.21)$ & $251(54.80)$ & $<0.001$ \\
\hline HbA1c (\%) & / & $5.80 \pm 0.79^{a}$ & $6.91 \pm 1.22$ & $<0.001$ \\
\hline Glycemia (mg/dL) & $107.0 \pm 24.3$ & $107.0 \pm 24.3$ & $131.3 \pm 40.3$ & $<0.001$ \\
\hline
\end{tabular}

$B M I$ Body mass index, COPD chronic obstructive pulmonary disease, BIMA bilateral internal mammary artery bypass grafting

adata from 129 non-diabetes patients

Values are presented as mean \pm SD or $n(\%)$

$P<0.05$ was considered significant

wound complications as a function of HbA1c and preoperative glycemia are represented in Figs. 1 and 2.

Within the group of diabetes patients, those who developed SWC were younger $(65.4 \pm 9.18$ vs $67.7 \pm 9.03$ years, $p=0.037)$, were more often female $(31.7 \%$ vs $19.7 \%, p=$ $0.017)$, had a higher BMI $(30.3 \pm 5.24$ vs $27.4 \pm 4.70, p<$ 0.001 ), underwent less frequently graft skeletonisation (13.4\% vs $27.1 \%, p=0.009$ ), and the use of BIMA grafts was more often employed in this patient group $(70.7 \%$ vs $51.3 \%, p=0.001$ ) (Table 4). There was a trend of higher HbA1c in those who developed SWC $(7.21 \pm 1.43 \%$ vs $6.85 \pm 1.16 \%, p=0.081)$. The unadjusted models revealed that higher HbA1c was significantly associated with a higher incidence of SWC $(p=0.018)$ as well as a higher grade of SWC $(p=0.014)$. However, the significance of this association disappeared in the adjusted model for incidence of SWC (OR 1.22, 95\% CI 1.00;1.49, $p=0.054$ ), whereas it remained for grade of SWC (OR 1.23, 95\% CI $1.01 ; 1.48, p=0.035)$. Diabetes patients who developed SWC had similar preoperative glycemia $(133.8 \pm 45.6 \mathrm{mg} /$ $\mathrm{dL}$ vs $130.8 \pm 39.1 \mathrm{mg} / \mathrm{dL}$ ). The models revealed no association between preoperative glycemia and incidence $(p=$ $0.673)$ nor grade $(p=0.800)$ of SWC.

Within the group of non-diabetes patients, those who developed SWC had a higher BMI $\left(28.0 \pm 4.70 \mathrm{~kg} / \mathrm{m}^{2}\right.$ vs $\left.26.4 \pm 3.93 \mathrm{~kg} / \mathrm{m}^{2}\right)$ and a higher use of BIMA $(78.2 \%$ vs $62.6 \%, p<0.001)$. Preoperative glycemia was similar $(106.1 \pm 21.6 \mathrm{mg} / \mathrm{dL}$ vs $107.1 \pm 24.6 \mathrm{mg} / \mathrm{dL}, p=0.996)$. In addition, 129 of the non-diabetes patients had HbA1c, showing similar values in the SWC and no SWC group

Table 3 Outcomes: sternal wound complication incidence and grade

\begin{tabular}{|c|c|c|c|c|}
\hline Variable & All $(n=1774)$ & Non-diabetes $(n=1316)$ & Diabetes $(n=458)$ & $P$ \\
\hline SWC incidence & $215(12.12)$ & $133(10.11)$ & $82(17.90)$ & 0.067 \\
\hline SWC grade & & & & $<0.001$ \\
\hline 1 & $85(4.79)$ & $59(4.48)$ & $26(5.68)$ & 0.303 \\
\hline 2 & $36(2.03)$ & $23(1.75)$ & $13(2.84)$ & 0.154 \\
\hline 3 & $66(3.72)$ & $33(2.51)$ & $33(7.21)$ & $<0.001$ \\
\hline 4 & $28(1.58)$ & $18(1.37)$ & $10(2.18)$ & 0.228 \\
\hline
\end{tabular}

SWC sternal wound complication, $\mathrm{Cl}$ confidence interval

Values are presented as mean \pm SD or $n(\%)$ if not otherwise specified

$P<0.05$ was considered significant 
Table 4 Comparison between patients with and without sternal wound complications

\begin{tabular}{|c|c|c|c|c|c|c|c|c|c|}
\hline \multirow[t]{2}{*}{ Variable } & \multicolumn{3}{|c|}{ All $(n=1774)$} & \multicolumn{3}{|c|}{ Non-diabetes $(n=1316)$} & \multicolumn{3}{|c|}{ Diabetes $(n=458)$} \\
\hline & $\begin{array}{l}\text { No SWC } \\
(n=1559)\end{array}$ & $\begin{array}{l}\text { SWC }(n= \\
215)\end{array}$ & $P$ & $\begin{array}{l}\text { No SWC }(n= \\
1183)\end{array}$ & $\begin{array}{l}\text { SWC }(n= \\
133)\end{array}$ & $P$ & $\begin{array}{l}\text { No SWC }(n= \\
376)\end{array}$ & $\begin{array}{l}\text { SWC }(n= \\
82)\end{array}$ & $P$ \\
\hline Age, years & $67.9 \pm 9.62$ & $67.1 \pm 9.85$ & 0.212 & $68.0 \pm 9.81$ & $68.2 \pm 10.1$ & 0.890 & $67.7 \pm 9.03$ & $65.4 \pm 9.18$ & 0.037 \\
\hline Male gender & $1276(81.9)$ & $157(73.0)$ & 0.002 & $974(82.3)$ & $101(75.9)$ & 0.071 & $302(80.3)$ & $56(68.3)$ & 0.017 \\
\hline $\mathrm{BMI}, \mathrm{kg} / \mathrm{m}^{2}$ & $26.7 \pm 4.15$ & $28.9 \pm 5.03$ & $\begin{array}{l}< \\
0.001\end{array}$ & $26.4 \pm 3.93$ & $28.0 \pm 4.70$ & $\begin{array}{l}< \\
0.001\end{array}$ & $27.4 \pm 4.70$ & $30.3 \pm 5.24$ & $\begin{array}{l}< \\
0.001\end{array}$ \\
\hline BMI group & & & $\begin{array}{l}< \\
0.001\end{array}$ & & & $\begin{array}{l}< \\
0.001\end{array}$ & & & $\begin{array}{l}< \\
0.001\end{array}$ \\
\hline$<25$ & $439(29.8)$ & $47(22.3)$ & & 355 (31.8) & $35(26.9)$ & & $84(23.5)$ & $12(14.8)$ & \\
\hline $25-29$ & $710(48.2)$ & $79(37.4)$ & & $541(48.5)$ & $52(40.0)$ & & $169(47.2)$ & $27(33.3)$ & \\
\hline $30-34$ & $277(18.8)$ & $54(25.6)$ & & $189(17.0)$ & $31(23.9)$ & & $88(24.6)$ & $23(28.4)$ & \\
\hline$>34$ & $47(3.2)$ & $31(14.7)$ & & $30(2.7)$ & $12(9.2)$ & & $17(4.8)$ & $19(23.5)$ & \\
\hline Urgent surgery & $756(48.5)$ & $108(50.2)$ & 0.632 & $562(47.5)$ & $\begin{array}{l}68 / 133 \\
(51.13)\end{array}$ & 0.428 & $194(51.6)$ & $40(48.8)$ & 0.644 \\
\hline $\begin{array}{l}\text { Oral } \\
\text { corticosteroids }\end{array}$ & $123(7.9)$ & $22(10.2)$ & 0.240 & $88(7.4)$ & $\begin{array}{l}15 / 133 \\
(11.28)\end{array}$ & 0.118 & $35(9.3)$ & $7(8.5)$ & 0.826 \\
\hline Transplantation & $12(0.8)$ & $4(1.9)$ & 0.113 & $7(0.6)$ & $1(0.8)$ & 0.822 & $5(1.3)$ & $3(3.7)$ & 0.145 \\
\hline COPD & $95(6.1)$ & $15(7.0)$ & 0.615 & $67(5.7)$ & $11(8.3)$ & 0.227 & $28(7.5)$ & $4(4.9)$ & 0.408 \\
\hline Skeletonisation & $346(22.2)$ & $38(17.7)$ & 0.131 & $244(20.6)$ & $27(20.3)$ & 0.930 & $102(27.1)$ & $11(13.4)$ & 0.009 \\
\hline BIMA & $934(59.9)$ & $162(75.4)$ & $\begin{array}{l}< \\
0.001\end{array}$ & $741(62.6)$ & $104(78.2)$ & $\begin{array}{l}< \\
0.001\end{array}$ & $193(51.3)$ & $58(70.7)$ & 0.001 \\
\hline HbA1c (\%) & $6.60 \pm 1.18$ & $7.03 \pm 1.42$ & 0.007 & $5.80 \pm 0.82^{\mathrm{a}}$ & $5.80 \pm 0.47^{\mathrm{a}}$ & 0.757 & $6.85 \pm 1.16^{\mathrm{a}}$ & $7.21 \pm 1.43^{\mathrm{a}}$ & 0.081 \\
\hline Glycemia (mg/dL) & $112.8 \pm 30.5$ & $116.6 \pm 35.5$ & 0.094 & $107.1 \pm 24.6$ & $106.1 \pm 21.6$ & 0.996 & $130.79 \pm 39.1$ & $133.8 \pm 45.6$ & 0.800 \\
\hline
\end{tabular}

$B M I$ Body mass index, COPD chronic obstructive pulmonary disease, BIMA bilateral internal mammary artery bypass grafting

${ }^{\text {a }}$ data from 129 non-diabetes patients

Values are presented as mean \pm SD or $\mathrm{n}(\%)$

$P<0.05$ was considered significant

$(5.80 \pm 0.47 \%$ vs $5.80 \pm 0.82 \%, p=0.757)$. None of the models revealed an association between $\mathrm{HbA1c}$ or preoperative glycemia and incidence $(p=0.794$ and $p=$ 0.972 , respectively) nor grade $(p=0.875$ and $p=0.950$, respectively) of SWC.

\section{Interaction models}

Variables that significantly modified the association of HbA1c and glycemia with the incidence of SWC are listed in Table 6. In the full study cohort, there was a significant interaction of age group with $\operatorname{HbA1c}(p=$ 0.021); higher HbA1c was significantly associated with a higher incidence of SWC (OR 1.41, 95\% CI 1.17;1.71, $p<0.001)$ in patients $<70$ years old, whereas there was no association in patients $\geq 70$ years old (Fig. 3 ). A similar interaction was seen within the subgroup of diabetes $(p=0.021)$. In the full study population, there was also a significant interaction of urgent surgery with $\mathrm{HbAlc}$

Table 5 Association of hemoglobin A1c and glycemia with incidence and grade of sternal wound complications

\begin{tabular}{|c|c|c|c|c|c|c|c|c|c|c|c|c|c|}
\hline \multirow[t]{2}{*}{ Variable } & & \multicolumn{4}{|c|}{ All $(n=1774)$} & \multicolumn{4}{|c|}{ Non-diabetes $(n=1316)$} & \multicolumn{4}{|c|}{ Diabetes $(n=458)$} \\
\hline & & Incidence & $P$ & Grade & $P$ & Incidence & $P$ & Grade & $P$ & Incidence & $P$ & Grade & $P$ \\
\hline \multirow[t]{2}{*}{$\mathrm{HbA1c}(\%)^{a}$} & $\begin{array}{l}\text { Non- } \\
\text { adjusted }\end{array}$ & $\begin{array}{l}1.28(1.09 ; \\
1.50)\end{array}$ & 0.003 & $\begin{array}{l}1.29(1.10 ; \\
1.50)\end{array}$ & 0.002 & $\begin{array}{l}1.00(0.47 ; \\
2.13)\end{array}$ & 0.992 & $\begin{array}{l}1.01(0.48 ; \\
2.11)\end{array}$ & 0.979 & $\begin{array}{l}1.25(1.04 ; \\
1.49)\end{array}$ & 0.018 & $\begin{array}{l}1.249(1.05 \\
1.49)\end{array}$ & 0.014 \\
\hline & Adjusted $^{\mathrm{b}}$ & $\begin{array}{l}1.24(1.04 ; \\
1.48)\end{array}$ & 0.016 & $\begin{array}{l}1.25(1.06 ; \\
1.48)\end{array}$ & 0.010 & $\begin{array}{l}0.85(0.24 \\
2.98)\end{array}$ & 0.794 & $\begin{array}{l}0.91(0.30 \\
2.80)\end{array}$ & 0.875 & $\begin{array}{l}1.22 \text { (1.00; } \\
1.49)\end{array}$ & 0.054 & $\begin{array}{l}1.23(1.01 ; \\
1.48)\end{array}$ & 0.035 \\
\hline \multirow[t]{2}{*}{$\begin{array}{l}\text { Glycemia } \\
\text { (mg/dL) }\end{array}$} & $\begin{array}{l}\text { Non- } \\
\text { adjusted }\end{array}$ & $\begin{array}{l}1.43(0.94 ; \\
2.16)\end{array}$ & 0.093 & $\begin{array}{l}1.449(0.96 ; \\
2.19)\end{array}$ & 0.077 & $\begin{array}{l}0.82(0.37 ; \\
1.82)\end{array}$ & 0.630 & $\begin{array}{l}0.85 \\
1.86)\end{array}$ & 0.683 & $\begin{array}{l}1.20(0.67 ; \\
2.14)\end{array}$ & 0.539 & $\begin{array}{l}1.16(0.65 ; \\
2.07)\end{array}$ & 0.607 \\
\hline & Adjusted $^{\mathrm{b}}$ & $\begin{array}{l}1.51(0.95 ; \\
2.42)\end{array}$ & 0.082 & $\begin{array}{l}1.49(0.94 \\
2.37)\end{array}$ & 0.089 & $\begin{array}{l}0.98(0.39 \\
2.50)\end{array}$ & 0.972 & $\begin{array}{l}1.03(0.41 ; \\
2.58)\end{array}$ & 0.950 & $\begin{array}{l}1.15(0.60 ; \\
2.19)\end{array}$ & 0.673 & $\begin{array}{l}1.09(0.58 \\
2.05)\end{array}$ & 0.800 \\
\hline
\end{tabular}

${ }^{a}$ data from 458 diabetes patients and 129 non-diabetes patients, for a total of 587 patients who had HbA1c values available

badjusted for gender, BMI, and rate of BIMA use

$P<0.05$ was considered significant 


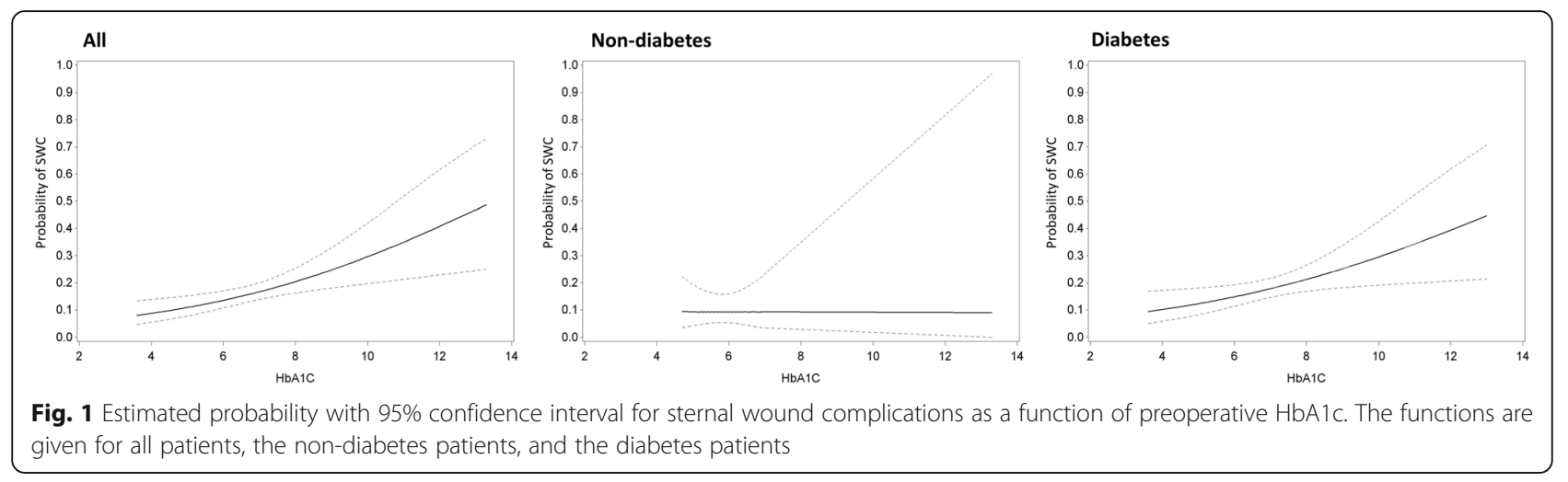

$(p=0.049)$; higher HbA1c was significantly associated with a higher incidence of SWC (OR 2.48, 95\% CI 1.26; $4.88, p=0.009$ ) if the surgery was not urgent, whereas it was not if the surgery was urgent $(p=0.914)$.

Within the subgroup of diabetes, a significant interaction of skeletonisation with preoperative glycemia was observed; higher glycemia was significantly associated with a higher incidence of SWC (OR 4.83, 95\% CI 1.28; 18.17, $p=0.020$ ) if skeletonisation was used, whereas no association was present if no skeletonisation was used $(p=0.802)$ (Fig. 4). There was also a significant interaction of BMI with preoperative glycemia; higher glycemia was significantly associated with a higher incidence of SWC (OR 2.19, 95\% CI 1.01;4.76, $p=0.047$ ) if BMI was $<30$, whereas no association was present if BMI was $\geq 30(p=0.223)$.

We found no significant interactions with gender, oral corticosteroids, transplantation, COPD, or BIMA.

\section{Discussion}

\section{Main findings}

This study, investigating 1774 consecutive patients who underwent $\mathrm{OPCAB}$ surgery between January 2010 and November 2016, showed that elevated HbA1c was significantly associated with a higher incidence and grade of SWC following OPCAB, although only in diabetes patients and patients younger than 70 years old. An association of preoperative glycemia was found only in patients who underwent non-urgent surgery, diabetes patients who received skeletonised grafts, and diabetes patients with a $\mathrm{BMI}<30$.

Patients who developed SWC were more likely to have diabetes, a higher BMI, to be of female gender, and more likely to receive BIMA grafts. Even after adjusting for these demographic differences, an increase in HbA1c remained significantly associated with an increased risk of SWC. Of note, diabetes patients who developed SWC were less likely to have received skeletonised grafts, which we have previously shown to be protective against SWC in this population [13].

Although the association between HbA1c and SWC was quite clear in the full study population and the subgroup of diabetes patients, the same relationship was not observed for non-diabetes patients. This finding is in accordance with other studies [14, 15]. Sato et al. [16] provided a potential explanation for this phenomenon by showing that there is a negative correlation of HbA1c with intraoperative insulin sensitivity in diabetes pateints but not in non-diabetes patients. Intraoperative insulin resistance in its turn was associated with an increased risk of infections after surgery. It has therefore been
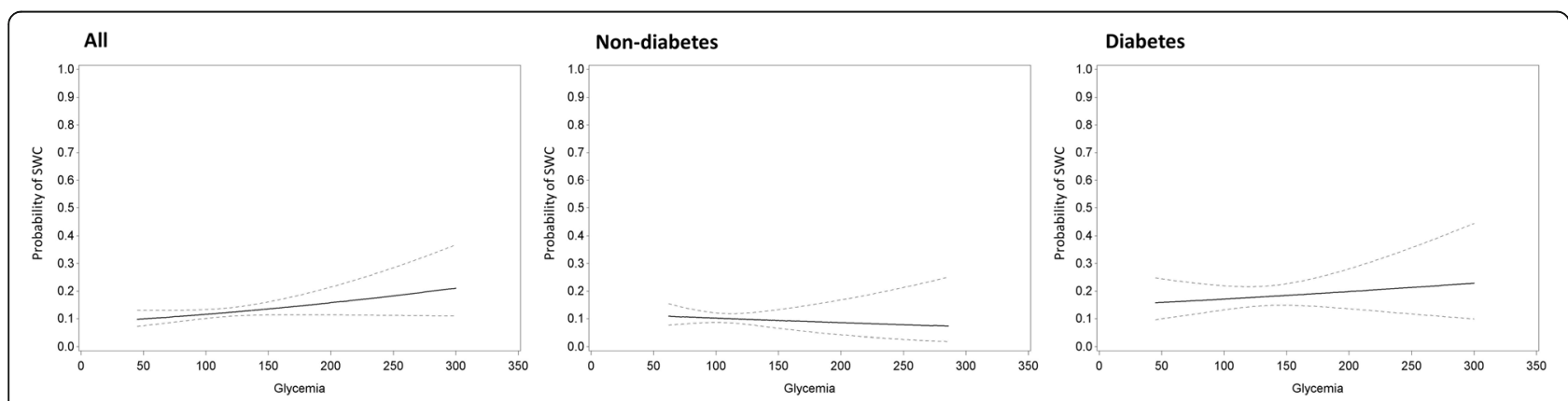

Fig. 2 Estimated probability with 95\% confidence interval for sternal wound complications as a function of preoperative glycemia. The functions are given for all patients, the non-diabetes patients, and the diabetes patients 
Table 6 Significant modifiers of the association of hemoglobin A1C and glycemia with incidence of sternal wound complications

\begin{tabular}{|c|c|c|c|c|c|c|}
\hline Population & Variable & $\begin{array}{l}\text { Interaction } \\
\text { with }\end{array}$ & $\begin{array}{l}P \\
\text { (interaction) }\end{array}$ & Stratification & $\begin{array}{l}\text { Odds ratio (effect of } \mathrm{HbA1c} \text { ) } \\
\text { glycemia) }\end{array}$ & $\begin{array}{l}\text { P (effect of HbA1c/ } \\
\text { glycemia) }\end{array}$ \\
\hline \multirow[t]{2}{*}{ All } & Age group & $\mathrm{HbA1c}$ & 0.021 & $<70$ years & $1.41(1.17 ; 1.71)$ & $<0.001$ \\
\hline & & & & $\geq 70$ years & $0.85(0.57 ; 1.25)$ & 0.405 \\
\hline \multirow[t]{2}{*}{ Diabetes } & Age group & $\mathrm{HbA1c}$ & 0.021 & $<70$ years & $1.38(1.11 ; 1.70)$ & 0.003 \\
\hline & & & & $\geq 70$ years & $0.80(0.52 ; 1.23)$ & 0.306 \\
\hline \multirow[t]{2}{*}{ All } & Urgent surgery & Glycemia & 0.049 & Urgent & $1.03(0.59 ; 1.80)$ & 0.914 \\
\hline & & & & Not urgent & $2.48(1.26 ; 4.88)$ & 0.009 \\
\hline \multirow[t]{2}{*}{ Diabetes } & Skeletonisation & Glycemia & 0.029 & Skeletonised & $4.83(1.28 ; 18.17)$ & 0.020 \\
\hline & & & & $\begin{array}{l}\text { Not } \\
\text { skeletonised }\end{array}$ & $0.92(0.47 ; 1.80)$ & 0.802 \\
\hline \multirow[t]{2}{*}{ Diabetes } & BMl & Glycemia & 0.029 & $\mathrm{BMI} \geq 30$ & $0.54(0.20 ; 1.46)$ & 0.223 \\
\hline & & & & $\mathrm{BMI}<30$ & $2.19(1.01 ; 4.76)$ & 0.047 \\
\hline
\end{tabular}

BMI Body mass index

$P<0.05$ was considered significant

suggested that impaired glucose tolerance during surgery is the actual cause of perioperative hyperglycemia and subsequent SWC, and that $\mathrm{HbA1c}$ is an adequate substrate biomarker in diabetes patients but not in nondiabetes patients [17].

Another factor that might in part explain the inability of the present study to find a significant association in the non-diabetes group is that HbA1 measurements were obtained in only a small subset of this group, as HbA1c is only reimbursed in Belgium for patients with known diagnosis of diabetes. The obtained values might therefore be biased because of the reason why they were ordered, which often is the clinical suspicion of diabetes mellitus. Indeed, 68 out of $129(52.7 \%)$ of these patients had a HbA1c between 5.7 and $6.4 \%$, suggesting that they had prediabetes [12]. A HbA1c higher than $6.5 \%$ was seen in 8 patients (6.2\%), indicating undiagnosed diabetes. Although this sample size was too low to perform separate analyses, a study by Lauruschkat et al. [18] previously showed that patients with undiagnosed diabetes had substantially higher morbidity and mortality rate.
This was confirmed in a study of the National Health and Nutrition Examination Surveys (NHANES), showing an increased all-cause mortality in undiagnosed diabetes [19]. The prevalences of undiagnosed diabetes in these studies were 5.2 and $4.7 \%$, respectively, corresponding well with our findings.

Interestingly, we found a significant interaction between age group and the association of HbA1c with SWC: higher HbA1c was significantly associated with a higher incidence of SWC in patients $<70$ years old, whereas there was no association in patients $\geq 70$ years old. Because the incidence of SWC was not significantly different between the two groups $(17.2 \%$ versus $14.0 \%$ for $<70$ and $\geq 70$ years, respectively, $p=0.288$ ), this most likely does not reflect an actual lower risk of SWC, but rather an inability of HbA1c to predict SWC in this elderly population. This might be because other risk factors for SWC, other than HbA1c, such as altered immune function, angiopathy, obesity, limited mobility, and malnutrition, are relatively more important in elderly, or because of the impaired basal glucose control with normal
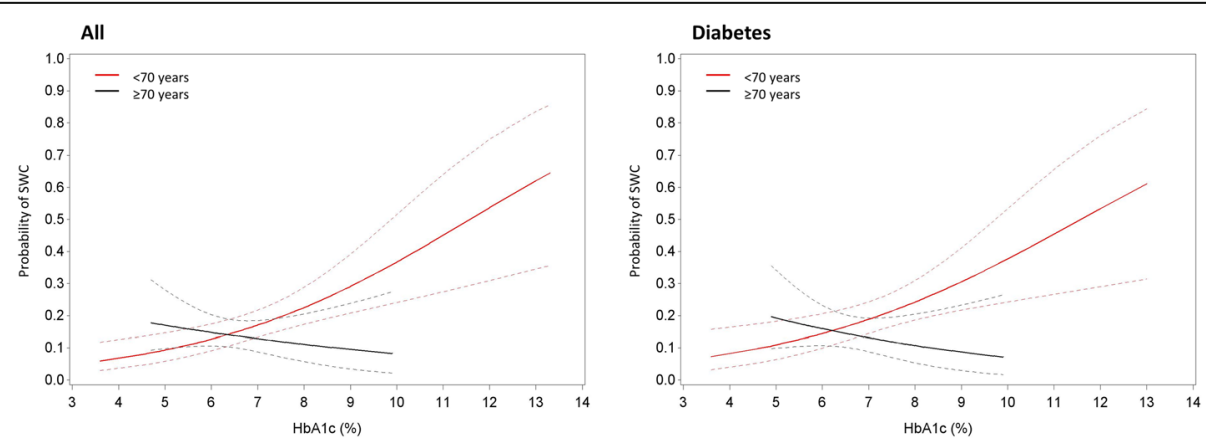

Fig. 3 Estimated probability with 95\% confidence interval for significant modifiers of the association of HbA1c with sternal wound complications. Estimated probabilities are stratified by age group ( $<70$ years old versus $\geq 70$ years old) for the full study population (left) and the diabetes population (right) 

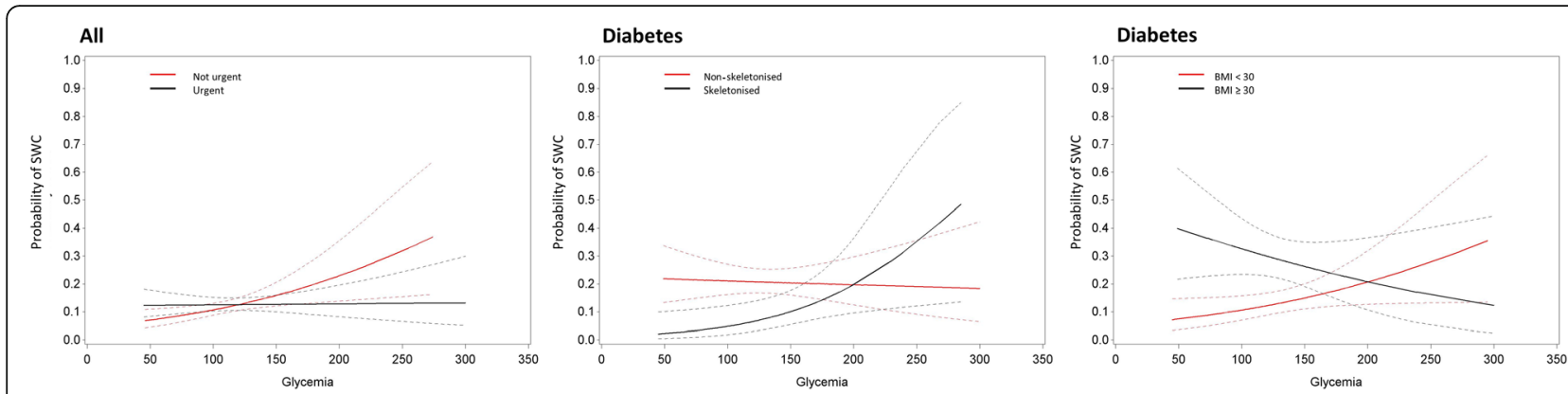

Fig. 4 Estimated probability with 95\% confidence interval for significant modifiers of the association of preoperative glycemia with sternal wound complications. Estimated probabilities are stratified by urgency (left; urgent versus not urgent), skeletonisation (middle; skeletonised versus not skeletonised), and diabetes (right; $\mathrm{BMI}<30$ versus BMI $\geq 30$ ) for the full study population (left) and the diabetes population (middle and right)

aging [20]. Nonetheless, our findings do not necessarily contradict the importance of intensive perioperative glucose control. In fact, HbA1c levels $>8.0 \%$ have been associated with increased risk of all-cause and cardiovascular mortality in older adults, highlighting the need for individualized glycemic targets at old age [19].

As glycemia is more sensitive to temporal changes than $\mathrm{HbA1c}$, it was expected that it would contain less predictive power for postoperative SWC. This was confirmed by our finding that in the overall study group, none of our models revealed an association between preoperative glycemia and incidence nor grade of SWC. However, after studying interaction terms, we were able to demonstrate that glycemia did correlate with SWC under certain conditions. Firstly, glycemia was found to be a useful predictor in a non-urgent setting. The stress associated with urgent interventions is known to cause transient disruption of blood glucose profiles, which might blunt their prognostic information [21]. In the setting of urgent surgery, HbA1c might therefore still be a better marker as it is more stable and more readily reflects chronic blood glucose levels. Secondly, glycemia was significantly associated with SWC in diabetes patients with skeletonized grafts or who had a $\mathrm{BMI}<30$. As demonstrated previously, skeletonisation exerts a protective effect against SWC following OPCAB; thus reducing other risk factors, the effect of dysregulated glycemia might be made more apparent [13]. Similarly, the convergence of multiple risk factors in obese (BMI > 30) patients with diabetes might lead to a blunting of the effect of glycemia on SWC.

\section{Limitations}

This study has some limitations. This was a retrospective observational study and might therefore be susceptible to confounding. However, we identified patient characteristics and used multivariable models to account for characteristics that were different between groups. Nevertheless, this does not exclude that there may have been unidentified confounders that we could not ajust for. As suggested above, only a small amount of the non-diabetes population had available $\mathrm{HbA1c}$ values, which might furthermore be biased by the reason for ordering this lab test. A prospective study might therefore be better suited to specifically investigate the role of preoperative HbA1c screening in a non-diabetes population. Finally, we only obtained preoperative laboratory data, and thus could not evaluate intraoperative or postoperative changes in glucose homeostasis.

\section{Conclusions}

In general, elevated $\mathrm{HbA1c}$ is significantly associated with a higher incidence and grade of SWC following OPCAB in diabetes patients, whereas glycemia is not. However, the association of HbA1c with SWC seems to be negligible in patients older than 70 years. Furthermore, glycemia might be a useful predictor of SWC under certain conditions: in patients who undergo nonurgent surgery, in diabetes patients who receive skeletonised grafts, and in diabetes patients with a $\mathrm{BMI}<30$.

\section{Abbreviations}

BIMA: Bilateral internal mammary artery; BMI: Body mass index; CABG: Coronary artery bypass graft; COPD: Chronic obstructive pulmonary disease; DM: Diabetes mellitus; HbA1c: Hemoglobin A1c; IMA: Internal mammary artery; OPCAB: Off-pump coronary artery bypass; SIMA: Single internal mammary artery; SWC: Sternal wound complication;

TX: Transplantion

\section{Acknowledgements}

J. Van den Eynde was supported by the Belgian American Educational Foundation.

\section{Authors' contributions}

JVDE, AV, DS, BM, TV, SJ, PV, and WO conceived the study. AW collected the data. JVDE, AW, and AL analysed the data, performed statistical analyses, and drafted the manuscript. DS, BM, SJ, PV, and WO gave important intellectual contribution and critically revised the manuscript. All authors read and approved the final manuscript.

Funding

No funding was involved in this study.

\section{Availability of data and materials}

The datasets used and analysed during the current study are available from the corresponding author on reasonable request. 


\section{Declarations}

\section{Ethics approval and consent to participate}

This study conforms to the ethical guidelines of the 1975 Declaration of Helsinki as reflected in a priori approval by the local Ethical Committee of the University Hospitals of Leuven.

\section{Consent for publication}

Not applicable.

\section{Competing interests}

The authors declare that they have no competing interests.

\section{Author details}

'Department of Cardiovascular Diseases, Research Unit of Cardiac Surgery, University Hospitals Leuven, Herestraat 49, 3000 Leuven, Belgium. ${ }^{2}$ Leuven Biostatistics and Statistical Bioinformatics Centre (L-BioStat), KU Leuven, Leuven, Belgium.

Received: 21 August 2020 Accepted: 9 July 2021

Published online: 20 July 2021

\section{References}

1. Zeitani J. Sternal Wound Complications. In: Plastic and Thoracic Surgery, Orthopedics and Ophthalmology. Cham: Springer; 2018. p. 229-39. https:// doi.org/10.1007/15695_2017 73.

2. Singh K, Anderson E, Harper JG. Overview and Management of Sternal Wound Infection. Semin Plast Surg. 2011;25(01):025-33. https://doi.org/10.1 055/s-0031-1275168.

3. Cayci C, Russo M, Cheema F, Martens T, Ozcan V, Argenziano M, et al. Risk analysis of deep sternal wound infections and their impact on long-term survival: a propensity analysis. Ann Plast Surg. 2008;61(3):294-301. https:// doi.org/10.1097/SAP.0b013e31815acb6a.

4. Filsoufi F, Castillo JG, Rahmanian PB, Broumand SR, Silvay G, Carpentier A, et al. Epidemiology of deep sternal wound infection in cardiac surgery. $J$ Cardiothorac Vasc Anesth. 2009;23(4):488-94. https://doi.org/10.1053/j.jvca.2 009.02.007.

5. Sachithanandan A, Nanjaiah P, Nightingale P, Wilson IC, Graham TR, Rooney $S J$, et al. Deep sternal wound infection requiring revision surgery: impact on mid-term survival following cardiac surgery. Eur I Cardiothorac Surg. 2008; 33(4):673-8. https://doi.org/10.1016/j.ejcts.2008.01.002.

6. Blakytny R, Jude E. The molecular biology of chronic wounds and delayed healing in diabetes. Diabet Med. 2006;23(6):594-608. https://doi.org/1 0.1111/j.1464-5491.2006.01773.x.

7. Raza S, Sabik JF, Ainkaran P, Blackstone EH. Coronary artery bypass grafting in diabetics: A growing health care cost crisis. J Thorac Cardiovasc Surg. 2015;150(2):304-312.e2. https://doi.org/10.1016/j.jtcvs.2015.03.041.

8. Mannucci E, Dicembrini I, Lauria A, Pozzilli P. Is glucose control important for prevention of cardiovascular disease in diabetes? Diabetes Care. 2013; 36(SUPPL.2):S259-63. https://doi.org/10.2337/dcS13-2018.

9. Lazar HL, Chipkin SR, Fitzgerald CA, Bao Y, Cabral H, Apstein CS. Tight glycemic control in diabetic coronary artery bypass graft patients improves perioperative outcomes and decreases recurrent ischemic events. Circulation. 2004;109(12):1497-502. https://doi.org/10.1161/01.CIR.000012174 7.71054.79.

10. Lazar HL, McDonnell MM, Chipkin S, Fitzgerald C, Bliss C, Cabral H. Effects of aggressive versus moderate glycemic control on clinical outcomes in diabetic coronary artery bypass graft patients. Ann Surg. 2011;254:458-64. https://doi.org/10.1097/SLA.0b013e31822c5d78.

11. Borger MA, Rao V, Weisel RD, et al. Deep sternal wound infection: risk factors and outcomes. Ann Thorac Surg. 1998;65(4 SUPPL):1050-6. https:// doi.org/10.1016/s0003-4975(98)00063-0.

12. American Diabetes Association. 6. Glycemic Targets: Standards of Medical Care in Diabetes-2020. Diabetes Care. 2020;43(Suppl 1):S66-76. https://doi. org/10.2337/dc20-5006

13. Van den Eynde J, Heeren A, Szecel D, et al. Skeletonisation contributing to a reduction of sternal wound complications: a retrospective study in OPCAB patients. J Cardiothorac Surg. 2019;14(1):1-11. https://doi.org/10.1186/s1301 9-019-0985-9.

14. Narayan P, Kshirsagar N, Kumar Mandal C, et al. Preoperative glycosylated hemoglobin: a risk factor for patients undergoing coronary artery bypass.
Ann Thorac Surg. 2017;104(2):606-12. https://doi.org/10.1016/j.athoracsur.2 016.

15. Gatti G, Perrotti A, Reichart D, Maschietto L, Onorati F, Chocron S, et al. Glycated hemoglobin and risk of sternal wound infection after isolated coronary surgery. Circ J. 2017;81(1):36-43. https://doi.org/10.1253/circj.CJ-160778.

16. Sato H, Carvalho G, Sato T, Lattermann R, Matsukawa T, Schricker T. The Association of Preoperative Glycemic Control, intraoperative insulin sensitivity, and outcomes after cardiac surgery. J Clin Endocrinol Metab. 2010;95(9):4338-44. https://doi.org/10.1210/jc.2010-0135.

17. Tsuruta R, Miyauchi K, Yamamoto T, Dohi S, Tambara K, Dohi T, et al. Effect of preoperative hemoglobin A1c levels on long-term outcomes for diabetic patients after off-pump coronary artery bypass grafting. J Cardiol. 2011;57(2): 181-6. https://doi.org/10.1016/j.jjcc.2010.11.003.

18. Lauruschkat AH, Arnrich B, Albert AA, Walter J̈A, Amann B, Rosendahl UP, et al. Prevalence and risks of undiagnosed diabetes mellitus in patients undergoing coronary artery bypass grafting. Circulation. 2005;112(16):2397402. https://doi.org/10.1161/CIRCULATIONAHA.105.534545.

19. Palta P, Huang ES, Kalyani RR, Golden SH, Yeh HC. Hemoglobin A1c and mortality in older adults with and without diabetes: results from the national health and nutrition examination surveys (1988-2011). Diabetes Care. 2017:40(4):453-60. https://doi.org/10.2337/dci16-0042.

20. Kaye KS, Schmader KE, Sawyer R. Surgical site infection in the elderly population. Clin Infect Dis. 2004;39(12):1835-41. https://doi.org/10.1086/42 5744

21. Duggan EW, Carlson K, Umpierrez GE. Perioperative hyperglycemia management: an update. Anesthesiology. 2017;126(3):547-60. https://doi. org/10.1097/ALN.0000000000001515.

\section{Publisher's Note}

Springer Nature remains neutral with regard to jurisdictional claims in published maps and institutional affiliations.

Ready to submit your research? Choose BMC and benefit from

- fast, convenient online submission

- thorough peer review by experienced researchers in your field

- rapid publication on acceptance

- support for research data, including large and complex data types

- gold Open Access which fosters wider collaboration and increased citations

- maximum visibility for your research: over $100 \mathrm{M}$ website views per year

At $\mathrm{BMC}$, research is always in progress.

Learn more biomedcentral.com/submissions 